\title{
DOES THE ADDITION OF THE NEW PROGNOSTIC BIOMARKERS ON EIGHTH EDITION OF AJCC CHANGE BREAST CARCINOMAS STAGING?
}

\author{
Jéssica E. P. Ramos ${ }^{1,2}$, Cesar A. S. T. Vilanova-Costa1,3, Juliana F. Paes ${ }^{4}$, Vera A. Saddi 1,2,4,5 \\ ${ }^{1}$ Laboratório de Genética e Biodiversidade, Programa de Pós-graduação em Ciências Ambientais e Saúde, Universidade \\ Católica de Goiás - Goiânia (GO), Brazil. \\ Escola de Ciências Médicas, Farmacêuticas e Biomédicas, Pontifícia Universidade Católica de Goiás - Goiânia (GO), Brazil. \\ ${ }^{3}$ Laboratório de Biologia Tumoral, Hospital Araújo Jorge, Associação de Combate ao Câncer em Goiás - Goiânia (GO), Brazil. \\ 4Programa de Pós-graduação em Ciências da Saúde, Universidade Federal de Goiás - Goiânia (GO), Brazil. \\ ${ }^{5}$ Laboratório de Oncogenética e Radiobiologia, Instituto de Ensino e Pesquisa, Associação de Combate ao Câncer em \\ Goiás - Goiânia (GO), Brazil.
}

Tumor staging plays a pivotal role in the treatment against cancer. The new revision of AJCC included histologic grade, estrogen receptor (ER), progesterone receptor (PgR), HER2 and Ki-67 expression as prognostic biomarkers for breast câncer (BC) staging. This study aimed to evaluate if the new prognostic biomarkers included on the eighth edition of AJCC are sufficient to change BC staging. Clinicopathological and immunohistochemical characteristics of 92 BCs, 36 triple-negative (TNBC) and 56 non-triple-negative (NTNBC) breast tumors, were collected from medical records of the Pathology Department of Araújo Jorge Hospital-ACCG (Goiânia, Goiás, Brazil). The study was approved by the institutional Ethics Committee of Araújo Jorge Hospital (Report $n^{\circ}$ 948.930, 2015). BCs were evaluated under the recommendations of the seventh edition of AJCC and then compared to new (eighth) edition criteria. Results show that $2.8 \%$ of TNBC progressed from stages I-II to III-IV ( $\mathrm{p}=0.81$ ) and $5.4 \%$ of NTNBC regressed from stages III-IV to I-II ( $\mathrm{p}=0.57)$, revealing that the addition of new prognostic biomarkers abovementioned had no influence on BC staging. It is well known that, compared with other tumor types, TNBCs have high expression of cyclin E, caveolins 1 and 2, P-cadherin; low expression of E-cadherin and cyclin D1. TNBCs also present aberrant expression levels for p53, BRCA1 and PARP. These biomarkers can be important on $\mathrm{BC}$ stanging and the lack of a more comprehensive assessment of possible $\mathrm{BC}$ prognostic biomarkers can be a weakness of new AJCC version. 